\title{
Correction to: MiRNA-195-5p Functions as a Tumor Suppressor and a Predictive of Poor Prognosis in Non-small Cell Lung Cancer by Directly Targeting CIAPIN1
}

Jing Zheng ${ }^{1} \cdot$ Tingting $X u^{1} \cdot$ Feng Chen ${ }^{1} \cdot$ Ying Zhang ${ }^{1}$

Published online: 5 February 2020

(C) Arányi Lajos Foundation 2020

Correction to: Pathology \& Oncology Research(2019)25:1181-1190

https://doi.org/10.1007/s12253-018-0552-z

The original version of this article unfortunately contained an error in the affiliation section.

The affiliation should have been Department of Respiratory Medicine, Taizhou Municiple Hospital, Zhejiang, China.

The corrected affiliation is shown below.

The online version of the original article can be found at https://doi.org/ $10.1007 / \mathrm{s} 12253-018-0552-\mathrm{z}$

Tingting Xu

Xu_tingting09@126.com

1 Department of Respiratory Medicine, Taizhou Municiple Hospital, Zhejiang, China 